\title{
BezGlutenu Mobile App-Novelty on the Polish Market
}

\author{
Aleksandra Grabowicz* and Grażyna Czaja-Bulsa
}

Department of Pediatric Diseases and Pediatric Nursing. Clinic of Pediatrics, Gastrology and Rheumatology. Pomeranian Medical University, Szczecin, Poland

\begin{abstract}
The bezGlutenu app is the first mobile app in Poland working under the official patronage of The Polish Coeliac Society. It enables searching through almost 1500 gluten-free products from 69 companies, certified with the Crossed Grain symbol. It is a helpful tool for people on a gluten-free diet.
\end{abstract}

Keywords: BezGlutenu app; Gluten-free diet

\section{Purpose of the Manuscript}

Purpose of this manuscript is to present bezGlutenu mobile app, a data base of gluten-free products certified with the official Crossed Grain symbol available in Poland. In this paper we discuss the app's novelty and utility especially in the context of unclear regulations regarding labelling of gluten-free products in Poland.

\section{Celiac Disease-The Tip of the Iceberg}

Celiac disease is one of the most common food intolerances. The prevalence of celiac disease has been estimated to approximate $1 \%$ of the world population. People across the globe, on nearly all continents, have been affected and the number of cases is expected to grow. It is roughly calculated that celiac disease affects 1 in 300 people in Europe and 1 in 130 people in the US. In Poland the number of cases is estimated to be at least 30.000 . It is crucial to indicate that properly diagnosed and treated cases comprise merely 20-30\%. In literature this percentage is referred to as 'tip of the iceberg'. Unfortunately, it is impossible to acquire specific data as there is no official record of the number of people affected by celiac disease [1-3].

\section{Gluten and its Health Implications}

Celiac disease is gluten-related food intolerance with both genetic and autoimmune background. In patients with celiac disease the consumption of gluten (a protein found in wheat, barley, rye and other grains) triggers inflammation in the small intestine that results in various structural, functional and histopathological changes in the intestines. These changes lead to nutritional deficiencies due to decrease of absorption surface. Long term exposition to gluten results in malnutrition and various general complications. As gluten plays a crucial role as a trigger of inflammatory process, life-long strict gluten free diet remains the only treatment for celiac disease [4].

\section{Misleading Labeling-Practical Problem for the Patient}

The Crossed Grain logo is the most trusted symbol by people who are on a gluten-free diet for medically justified reasons. It is a guarantee of safety and quality which is acknowledged by patients themselves. It serves as a quick reference tool helping to determine the gluten status of the product. The Crossed Grain symbol is a trademark registered across the European Union. It can be used only after obtaining a license strictly supervised by The Association of European Coeliac Societies (AOECS) and its Member societies. In Poland AOECS is represented by Polish Coeliac Society [5].

These statements are supported by research conducted by Coeliac UK, according to which people on a gluten-free diet actively search for the Crossed Grain symbol during shopping [6]. It is perceived as a valid way to inform the consumers of the product's safety. Moreover this study shows that the Crossed Grain symbol is trusted by $93 \%$ of the consumers. Nearly $90 \%$ of the consumers find the Crossed Grain symbol most useful when the products are not in the Free From aisle. It is of crucial importance, especially nowadays, as the gluten-free market is one of the most rapidly growing branches of trade and many producers of 'regular foods' add gluten-free products to their offer. According to Polish Celiac Society, 95\% of the consumers are more likely to buy certain product if it is licensed with the Crossed Grain Symbol [7]. It is of crucial importance to emphasize that not every product with crossed grain on the packaging is licensed by AOECS (or Member associations) as gluten-free. This is a result of arbitrariness of labeling used by food producers in Poland. In Poland labeling of gluten-free products is regulated by the Commission Implementing Regulation (EU) No 828/2014 of 30 July 2014 on the requirements for the provision of information to consumers on the absence or reduced presence of gluten in food [8].

According to this document: 'It should be ensured that (...) the provision of information on the absence or reduced presence of gluten in food continues to be based on the relevant scientific data and is not provided on a divergent basis which could mislead or confuse the consumers [8]. This document includes specific statements that can be used to provide information to consumers on the presence of gluten in food. Despite of the document unmistakably indicating the necessity of proper labeling of gluten-free products and that 'It is therefore necessary that uniform conditions for the application of these requirements to food information provided by food business operators on the absence or reduced presence of gluten in food are maintained in the Union'8 there are no clear regulations of graphic design on gluten-free products. Producers are obliged to label their product as gluten-free. There are no rules, however, specifying what kind of graphic design to use on the packaging. Therefore there is a multitude of variations of the crossed grain logo, each one with different design and colors, which can be used to label the product. This technique is used exclusively by producers who did not obtain

*Corresponding author: Aleksandra Grabowicz, Department of Pediatric Diseases and Pediatric Nursing. Clinic of Pediatrics, Gastrology and Rheumatology. Pomeranian Medical University, Szczecin, Poland, Tel: +48532-073-663; E-mail: aplikacja.celiakia@gmail.com

Received July 24, 2017; Accepted July 31, 2017; Published August 07, 2017

Citation: Grabowicz A, Czaja-Bulsa G (2017) BezGlutenu Mobile App-Novelty on the Polish Market. Health Care Current Reviews 5: 206. doi: 10.4172/23754273.1000206

Copyright: (c) 2017 Grabowicz A, et al. This is an open-access article distributed under the terms of the Creative Commons Attribution License, which permits unrestricted use, distribution, and reproduction in any medium, provided the original author and source are credited. 
the official license. Gluten-free trade market is one of the most rapidly growing branches of food industry in Poland. Over the last decade a significant increase in the number of gluten free producers has been observed, and yet finding specific products while shopping remains one of the most difficult aspects of living gluten-free [9].

\section{Patient Support and Education-Key to Success}

It is crucial to remember that gluten-free diet remains the only treatment for celiac disease [10]. Receiving the diagnosis of celiac disease (after years of waiting, in most cases) imposes on the patient the necessity to change previous lifestyle and adjust it to requirements set by the disease [11]. Education is one of the key elements of successful treatment of food-related disorders requiring an elimination diet, such as celiac disease. It not only enables the patients to learn new dietary skills but helps to maintain them which are one of the crucial elements of adaptation to a new lifestyle. It is especially important in newly diagnosed patients as it can positively change a patient's approach to a new dietary regime. In consequence, it can prevent the development of various health complications caused by even the smallest amount of gluten [12].

One of the most useful sources of information, according to patients themselves, is various celiac disease-focused organizations and charities. In their opinion the informational support and resources provided for the members is priceless [13]. The biggest nationwide organization supporting people on a gluten-free diet in Poland is the Polish Coeliac Society. It is the biggest non-profit organization providing all-encompassing support for celiac disease patients and their families. Presently is has over four thousands members from all over the country and their mission is 'to create a friendly environment for people on a gluten free diet in Poland' [14]. One of the most vital projects established by the Polish Coeliac Society is aimed at creating a Catalogue of Gluten-Free Products Available on the Polish Market. The latest version of the catalogue (updated on November 30th 2016) is available to download free of charge from the official website of the Polish Coeliac Society [15].

\section{BezGlutenu Mobile App-Catalogue 'to go'}

Catalogue of Gluten-Free Products Available on the Polish Market is available to download free of charge from the official website of the Polish Coeliac Society in 52-page long PDF format [15]. Some of the pages of the catalogue are additional content such as gluten-free product advertisements and interviews with some of the producers whose products are included on the list. In order to find a specific product the user has to go through almost the entirety of the catalogue. It is due to the fact that the products are sorted into vast categories for example baked goods/flours/special products or cold meats and meat based foods. Inside of those broad categories, products are categorized basing on the producer. This solution only lengthens the time needed to find a certain product as all the food items are listed based solely on their producer despite the fact that they in fact belong to various different categories. Let one of the many examples be that products such as: bread, jelly and instant soup are listed together in one category that is baked goods/flours/special products purely because they come from the same manufacturer. Such construction of the catalogue is misleading for the potential user as it is not clear where they should search for a specific product. Therefore users are forced to read through all 52 pages of the catalogue in order to find what they are looking for, which inevitably prolongs the whole process. Catalogue of Gluten-Free Products Available on the Polish Market is indisputably a very helpful source of information for patients on a gluten-free diet as it provides a truthful and reliable list of products licensed with the official The Association of European Coeliac Societies Crossed Grain symbol. However, the utility of the catalogue, especially in the 'outside of home' situations, remains questionable.

A suggested solution to the 'mobility' outside of home conditions is bezGlutenu mobile app16 (in English it means 'without gluten') created by Ms. Aleksandra Grabowicz, MA, PhD student at the Clinic of Pediatrics, Gastrology and Rheumatology of the Pomeranian Medical University in Szczecin, Poland.

The bezGlutenu mobile app has been available for free download from Google Play App Store since April 25th 2017 [16]. It is the first mobile app on the Polish market. It was based on the contents of the Catalogue of Gluten-Free Products Available on the Polish Market and as the first mobile app in Poland it was granted a patronage of the Polish Coeliac Society with permission to use the official Crossed Grain symbol. Polish Coeliac Society is the only organization in Poland authorized to give the permission to use the symbol under the terms of the contract with AOECS. What differentiates the PDF version of the catalogue from the mobile one is a significant growth in the number of categories and additional subcategories. Thanks to this solution products are grouped according to food categories rather than by their producers, which decreases the time needed to find a specific product. Users can search inside the category of their interest without having to go through the entire catalogue. An additional option in the app is a search engine which enables users to limit the search to the name of a product. As a result all the products matching our search are shown regardless of the producers. The description of each product comprises of its name, the logo of the company, the list of stores that the product is available to buy from and a direct link to the online store when applicable.

The additional advantage of the bezGlutenu mobile app is the possibility to update the products data base as soon as changes appear on the market. The gluten-free food market is one of the most dynamically developing branches of food industry in Poland. It is not uncommon that the license to use the Crossed Grain symbol is withdrawn as soon the producer fails to comply with the appropriate standards set by the Association of European Coeliac Societies. Moreover, new products and producers appear on the market almost daily. The original data base of the application can be manually adjusted by the administrator accordingly to the occurring changes. This includes options to: add/ remove new products and producers as well as edit the description details of every product such as its name, producer, availability in stores and the logo of its producer. Data in the catalogue provided by the Polish Coeliac Society were last updated on November 30th 2016, whereas information in the bezGlutenu app has been updated 17 times since its publication in the Google Play App Store on April 25th 2017 and is continuously updated every two weeks (the updated version of the data base is downloaded automatically after opening the app). As of July 2017 there are almost 1500 products from 69 companies available for search in the app. Time needed to adjust the renewed version of the Catalogue provided by the Polish Coeliac Society in PDF format to all dynamically occurring changes and to publish it is significantly prolonged. Since its publication date on April 25th 2017, the bezGlutenu mobile app has been downloaded by 1395 users from 4 countries. The users express their beliefs that this is a very helpful tool for people on a gluten-free diet.

\section{References}

1. Cielecka EK, Deren K, Grzegorczyk A (2010) Nadwrazliwosc pokarmowa Alergia Astma Immunologia-przeglad kliniczny 15:118-124. 
Citation: Grabowicz A, Czaja-Bulsa G (2017) BezGlutenu Mobile App-Novelty on the Polish Market. Health Care Current Reviews 5: 206. doi: $10.4172 / 2375-4273.1000206$

Page 3 of 3

2. Coutts A (2013) An overview of coeliac disease: Patterns, causes, symptoms and management. Gastrointest Nur 11: 26-30.

3. Reilly NR, Green PH (2012) Epidemiology and clinical presentations of celiac disease. Semin Immunopathol 34: 473-478.

4. Holmes S (2010) Coeliac disease: Symptoms, complications and patien support. Nurs Stand 24: 50-56.

5. Licensing the Crossed Grain symbol. Association of European Coeliac Societies.

6. Product certification information pack 2017. Coeliac UK.

7. Labeling of gluten-free products-Polish People's Association of Celiakia and gluten free.

8. European Commission (2014) Commission Implementing Regulation (EU) No $828 / 2014$ on the requirements for the provision of information to consumers on the absence or reduced presence of gluten in food. EUR-Lex.

9. Lange E (2013) Produkty bezglutenowe na rynku polskim. Handel Wewnetrzny 4: 83-95.
10. Vici G, Belli L, Biondi M, Polzonetti V (2016) Gluten free diet and nutrient deficiencies: A review. Clin Nutr 35: 1236-1241.

11. Picarelli A, Di Tola M, Borghini R, Isonne C, Donato G (2014) The high medical cost of celiac disease missed diagnosis: Is it cheaper to suspect it in time? Intern Med 4:155.

12. Zarkadas M, Dubois S, Maclsaac K, Cantin I, Rashid M, et al. (2013) Living with coeliac disease and a gluten-free diet: A Canadian perspective. J Hum Nutr Diet 26: 10-23.

13. Taylor E, Dickson-Swift V, Anderson K (2013) Coeliac disease: the path to diagnosis and the reality of living with the disease. J Hum Nutr Diet 26: 340 348

14. Polish People's Association of Celiakia and gluten free. Association activity.

15. List of Products with the Crossed Cross (2016) Polish People's Association of Celiakia and gluten free.

16. Grabowicz A (2017) bezGLUTENU. Version 1.03. Szczecin, Poland. 